\title{
Effect of Local District Expenditure in Education per Pupil on SAT Scores
}

\author{
Sofie Subiaur \\ Washington University in St. Louis \\ Yvonne Chen \\ Shenandoah University
}

Although it seems logical to assume a positive correlation between school funding and student achievement, past studies suggested mixed results. The purpose of this study is to reexamine this association between expenditure and performance. To that end, we investigated various assessment measures and found one that best served as a proxy for student achievement - average district SAT scores, converted from ACT. Data from several states were collected and analyzed initially, but we narrowed down to the State of Illinois - the location with most complete data for our research purpose and least data irregularities. Illinois is the chosen population, each school district represents a statistic, and there are three districts defined-rural, suburban, and populous. Our research concluded with a similar observation by the previous literature: more money invested in education does not necessarily translate to higher test scores. However, our finding suggests that when population is taken into account, the more populous the district is, the greater and positive correlation may be present between spending and performance.

Keywords: school funding, district spending, SAT, population strata, PISA

\section{INTRODUCTION AND LITERATURE REVIEW}

Common sense may suggest a linkage between increased school funding and higher student achievement; with more funds, schools can reduce class sizes, hire more qualified teachers, and invest in better educational resources such as quality content and technology. However, studies in the past have found little to no evidence of a direct relationship between the two. Kenneth Boulding (1972), for instance, reported that increases in education spending did not seem to be associated with greater student achievement. Eric Hanushek (1989 and 1996) stated in both of his research work that funding is not related to achievement in public education. Although influential in their time, these studies were likely biased as the researchers were known to have certain political ties. In contrast, Rob Greenwald, Larry Hedges and Richard Laine suggested that funding has significant effects (Biddle and Berliner, 2002). This issue remains unresolved as national per-pupil government expenditure grew to twice its size between the late 1960s and 1990s while National Assessment of Educational Progress Tests (NAEP) showed little improvement (Blagg and Chingos, 2017).

More recently, a 2016 study by Jackson, Johnson and Persico found that a $10 \%$ increase in per-pupil spending for all 12 years of schooling lead to .31 more completed years of education - a notable marker of student success. Another study focusing on the relationship between teacher quality (Darling-Hammond, 
2000) and student academic achievement found a strong relationship between the two. However, critics argue that increases in school funding may not be cost-effective; for example, by investing in teachers with higher educational attainment, whom research suggests are paid more but are not necessarily teaching more effectively (Chakraborty and Poggio, 2008). This would imply that increasing school-funding does not improve student academic success through hiring highly qualified teachers.

While the aforementioned research primarily focused on large-scale analysis, researchers have shifted to specific case studies to further illuminate correlation between school funding and student academic success. Part of the reason is because there is an acute lack of nation-wide comparable tests (the NAEP is a limited option, yet the sole one), but in localized regions they provide an easy measure of student success. In particular, a 2010 dissertation by Alan Bryant at Texas A\&M University focused on the relationship between per-pupil expenditures (PPE) and student success on a high-stakes End-of-Instruction test in the state of Oklahoma. With a Pearson Product Moment of -.027, he found no statistically significant correlation; only about $.07 \%$ of the variation in test scores could be explained by the variation in schoolfunding.

Similarly, recent studies in the U.S. continue to offer inconclusive evidence, which is not the case in other countries. In Columbia, for example, where a country-wide standardized test (the Saber 11) is administered, results indicated that public spending per teacher and spending per student were positively correlated to better learning outcomes (Recuero and Olaberria, 2018). In line with this is the fact that many of the countries that outrank the United States in the PISA scores (Blagg and Chingos, 2017) provide uniform funding to their public schools, which is different from the United States. This suggests that less discrepancy in funding may lead to more uniform - and higher - academic performance.

\section{RESEARCH FRAMEWORK}

The United States is arguably one of the wealthiest and most developed countries in the world. Yet on a worldwide comparison of education - notably, the PISA - the country ranks well below its peers and several developing countries. Despite recent teacher protests in underfunded school districts across the country, local governments are still reluctant to approve increased funding while their states sit on the lower ends of national rankings (Wendler, 2018). In Oklahoma, for instance, education budget increases fell short of teacher's demands; the state ranks number 47 in the country in terms of educational quality (Eger, 2017). The concern of the country losing its global competitiveness in education prompted this research study.

The objective of this study is to discern the local effect, if any, of school funding on markers of student achievement - specifically, the effect of local school district expenditure per student on average district SAT scores. We define the local district expenditure or school funding, as instructional and operational spending. The SAT tests are considered high stakes - and in this way, are similar to those utilized in the previous research (Bryant, 2010). However, these tests are more useful as a result of comparability across the nation; as they also affect students' college prospects, they may also be used to demonstrate education inequality across the United States. By narrowing down the scope of school funding and student performance, we hope to add clarity to previous research as well as illuminating the benefit of uniform school funding.

Given that the NAEP provided scores for only 20 of the most populous cities and the highly-regulated local PISA data is limited to only 4 states, the SAT scores became the best alternative; they are highly standardized and comparable across the nation. However, because the SAT is administered by the College Board, a private organization, they are allowed to collect a fee for releasing data. In this case, a school administrator must pay $\$ 95$ for a summary of a state's SAT results, making this data unattainable for us at this time. Fortunately, recent district SAT average scores were released online for the state of Illinois; we adopted this data for the research.

\section{Hypothesis}

Null Hypothesis: There is no statistically significant correlation between instructional and operational spending per student and average SAT score in districts of Illinois in every population strata. 
Alternate Hypothesis: There is a statistically significant correlation between instructional and operational spending per student and average SAT score in districts of Illinois in every population strata.

\section{Study Design}

Data collection of this study includes two parts: spending on education in each district per pupil and respective district average SAT scores. To stratify the data based on population, we also collected the population information of every district in the state of Illinois. For this data on the population size of every district, we used a website (http://proximityone.com/sd il.htm) that predicted population counts for 20162017 based on population data collected in 2009 by the American Community Survey, a nationwide census conducted every year. We found the rest of our data on the Illinois Report Card website; it contains data collected by the Illinois Board of Education for all students in the state in every school based on their data systems - an example of which is the Student Information System.

In order to carry out this study, we first organized the districts by population size and divide them into three strata: rural, suburban, and populous/urban. Then, from each strata, we randomly selected 25 districts using a random number generator; we selected the district on the list with the corresponding number. There were 872 districts listed which we split into three strata of 290 districts. We chose a sample size of 25 because it was less than 1/10 of the population, 290. After 25 districts were selected from each of the three strata, we used the Illinois Report Card Website to determine both the Instructional and Operational Spending per Student and the Average SAT score in the district. The website breaks down the SAT average score into two sections: Math and ELA. For our purposes, we summed up the two averages to create the overall average SAT score in the district.

The conditions we needed to check in order to perform regression inference were if the data was linear, independent, normal, of equal variance, and random. The conditions of independence and randomization were satisfied through our random sample. Observing our scatterplot confirmed that the data was linear and not exponential. We checked for normality by creating a histogram of the SAT scores from all samples in the figure below, FIGURE 1, to confirm the lack of clear skewness.

\section{FIGURE 1 \\ HISTOGRAM OF SAT SCORE DISTRIBUTION}

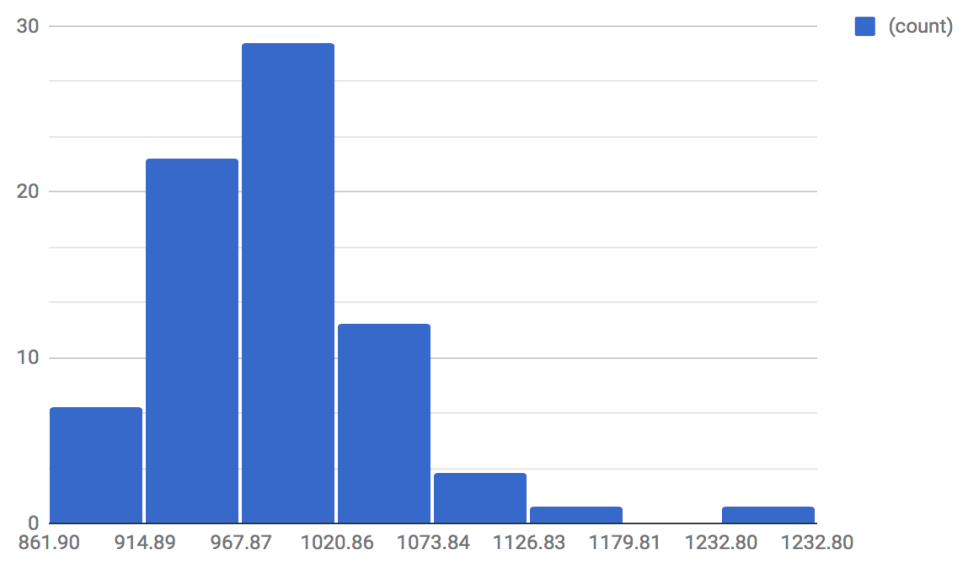

Although a slight skew might be observed, the Spearman's Rho coefficient ( $\mathrm{R}^{\wedge} 2$ value) is more robust against skewness than the Pearson correlation coefficient. Therefore, we decided to go ahead with the test. Next, we created a residual plot to confirm that the scatter plot was roughly the same on the either side of the $\mathrm{x}=0$ line. Once all the conditions were confirmed, we proceeded with the regression analysis.

After compiling tables for our raw data (available upon request), we created a scatterplot with the Xaxis (independent variable) as Instructional and Operational Spending per Student and Y-axis (dependent 
variable) as the Average SAT Score for the district. Trendlines for scatterplots were added and $\mathrm{R}^{\wedge} 2$ values recorded. In addition, we created a graph with all three strata's data overlaid and did a regression analysis for all data. This study attempted to establish correlation; thus, we designated an alpha value of 0.05 and used the Spearman's Rho coefficient ( $\mathrm{R}^{\wedge} 2$ value).

\section{RESULTS}

The raw data for corresponding SAT scores and spending per student for each selected districts in Illinois are available upon request. Samples are grouped based on three strata: rural, suburban, and populous (or urban) districts. Although $\mathrm{R}^{\wedge} 2$ values are small, certain trends are observed between the two variables.

FIGURE 2 illustrates the scatterplot of sample data for the $1^{\text {st }}$ strata of rural districts. It indicates the trendline and $\mathrm{R}^{\wedge} 2$ value. The data pattern demonstrates a slightly negative correlation between SAT scores and instructional and operational spending for students in rural districts of Illinois. Notes the value of $\mathrm{R}^{\wedge} 2$ is very low, which implies factors other than educational spending may better explain the SAT performance of students. Thus, it can be concluded that in rural areas, educational spending has almost no impact on the SAT scores.

\section{SAT VS. SPENDING IN RURAL DISTRICTS}

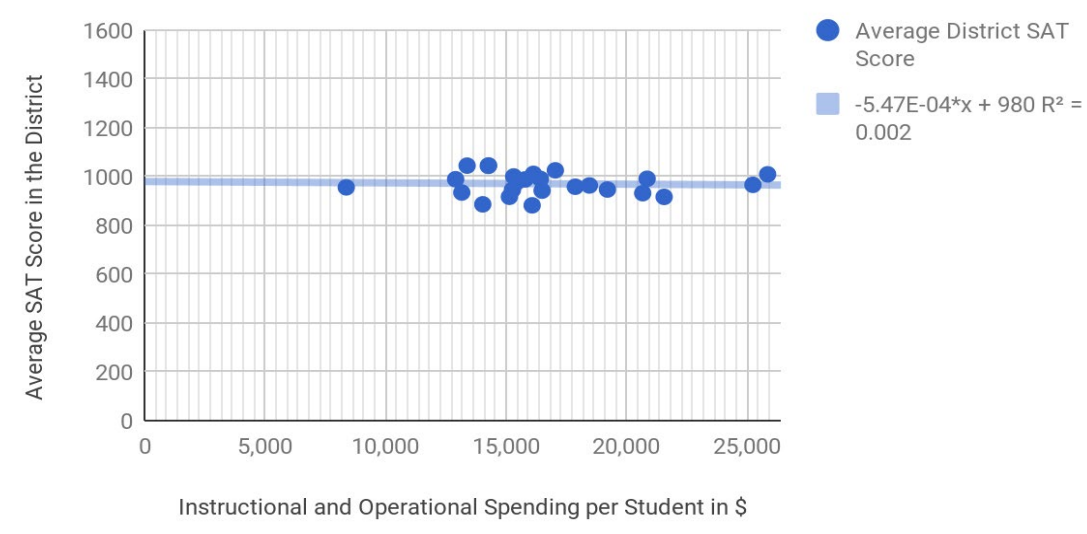

FIGURE 3 illustrates the scatterplot of sample data for the $2^{\text {nd }}$ strata of suburban districts. It also indicates the trendline and $\mathrm{R}^{\wedge} 2$ value. The data pattern demonstrates a likely positive correlation between SAT scores and instructional and operational spending for students in suburban districts of Illinois. Although $\mathrm{R}^{\wedge} 2$ value remains small, it is more significant than in the case of rural district $(0.2 \%$ versus $1.8 \%$ ). It can be concluded that in less rural area, education spending may have a positive, albeit very small, impact on SAT scores. 
FIGURE 3

\section{SAT VS. SPENDING IN SUBURBAN DISTRICTS}

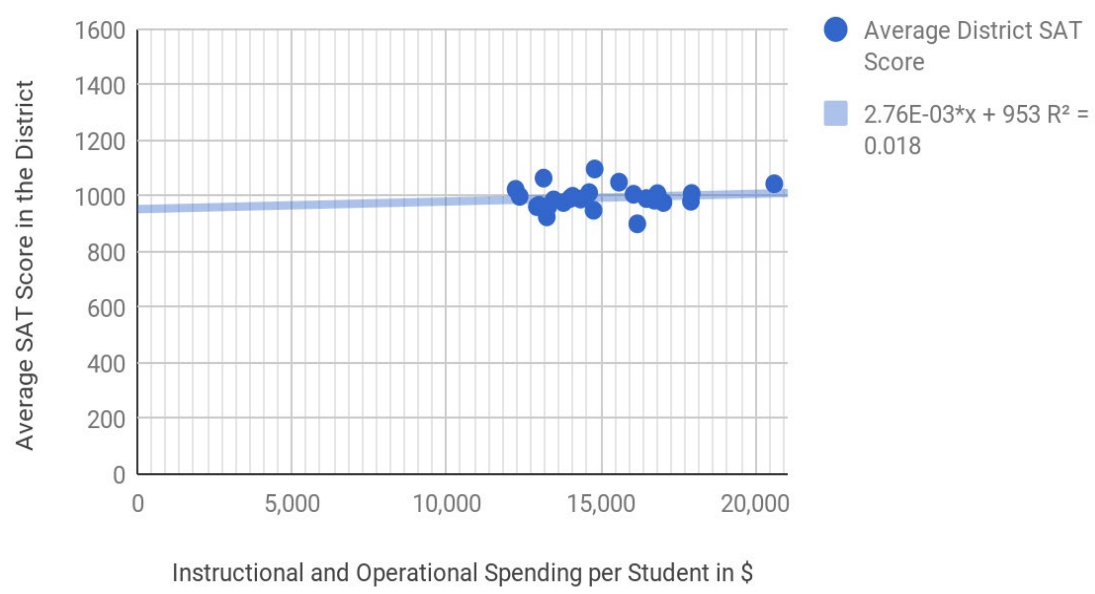

The following scatterplot for populous or urban districts of Illinois, FIGURE 4, continues the pattern and trend observed in FIGURE 3. That is, the less rural the area is, the higher impact educational spending may have on SAT scores. The data pattern demonstrates a clearly positive correlation between SAT scores and instructional and operational spending for students in districts of Illinois. Although $\mathrm{R}^{\wedge} 2$ value remains small, it is far more significant than in the case of rural district $(0.2 \%$ versus $3.3 \%)$. It can be concluded that in populous areas, educational spending has a greater and positive, albeit still small, impact on SAT scores.

FIGURE 4

SAT VS. SPENDING IN POPULOUS DISTRICTS

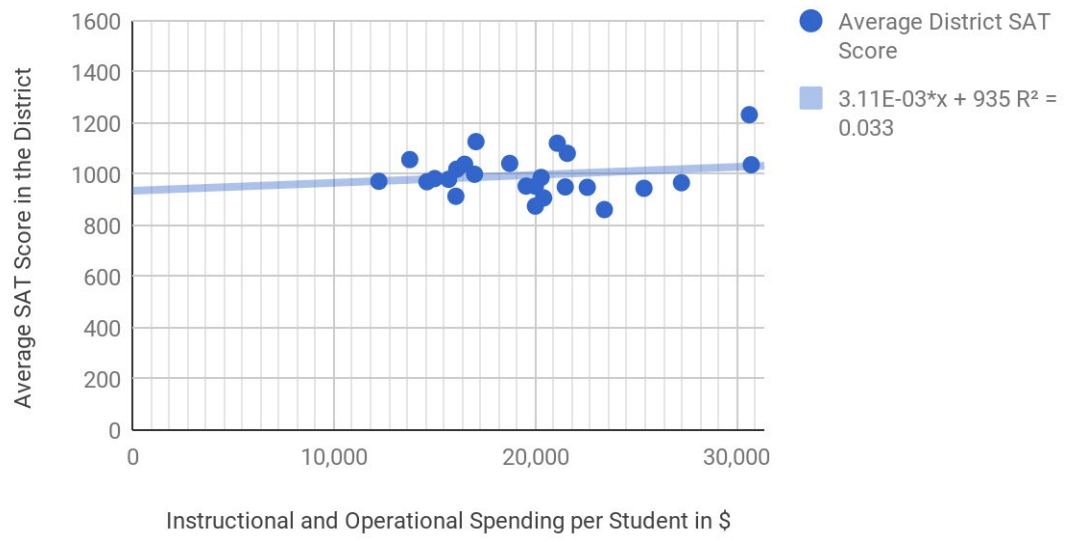

In FIGURE 5, data from all districts reveal a positive trend between SAT scores and instructional and operational spending. FIGURE 6 shows the respective regression line. The first strata, FIGURE 2, had a Spearman's Rho coefficient ( $\mathrm{R}^{\wedge} 2$ value) of 0.002 and an $\mathrm{r}$-value of -0.0447 , which indicates a very weak and negative correlation. The second strata, FIGURE 3, had an $\mathrm{R}^{\wedge} 2$ value of 0.018 and an r-value of 0.134 , which indicates a weak and positive correlation. The third and final strata, FIGURE 4, had an $\mathrm{R}^{\wedge} 2$ value of 0.033 and an $r$-value of 0.182 , which once again indicates a likely positive correlation. At the alpha $=.05$ level, with a sample size of 25 (as in each strata), the critical Spearman's Rho coefficient is .398; we decided to conduct a two-tailed test out of uncertainty of the directionality of results. Because our calculated values were all much smaller, we failed to reject the null hypothesis at the alpha $=.05$ level. For the plot with data from all the plots combined, our Spearman's Rho coefficient was .015 while the critical value for the alpha 
$=.05$ level shifted to .227 because the total sample size increased to 75 . Once again, this was not significant at the alpha $=.05$ level, which led to us unable to reject the null hypothesis of no-significant correlation between the two variables.

\section{FIGURE 5}

\section{SAT VS. SPENDING IN ALL DISTRICTS}

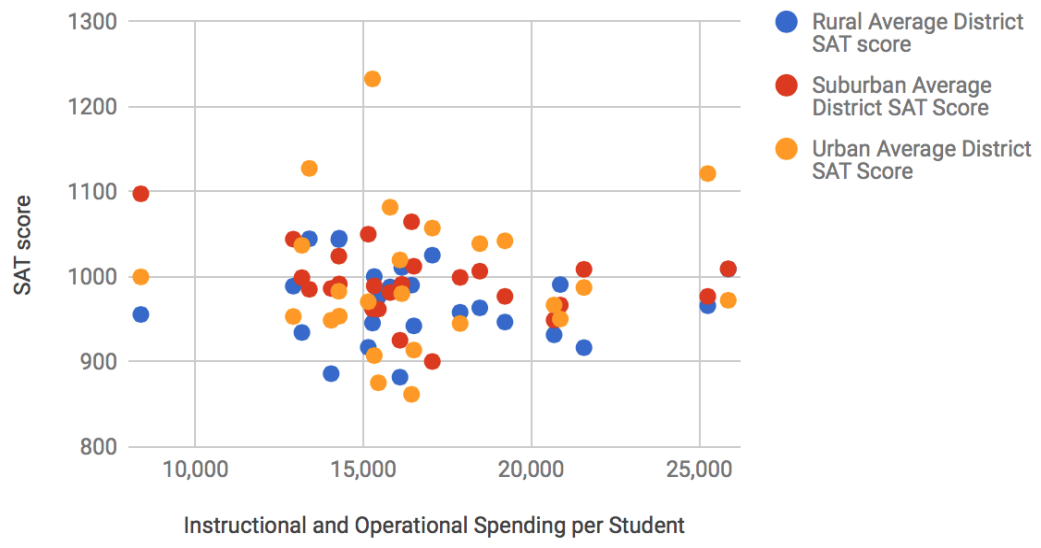

FIGURE 6

TREND FOR SAT VS. SPENDING IN ALL DISTRICTS

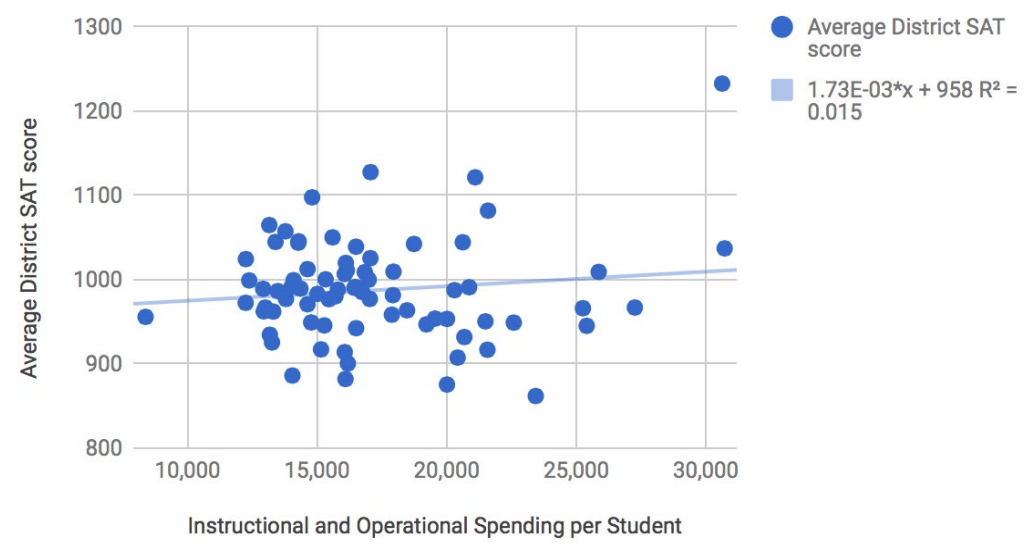

\section{DISCUSSION AND CONCLUDING REMAKRS}

The objective of this research was to discern the existence of a significant correlation between school district expenditure per pupil and student achievement, for which we adopted proxy values such as instructional \& operational spending and SAT scores. Our null hypothesis is that there is no significant correlation between District Instructional and Operational Spending per Student and respective Average District SAT Scores. Although trends were present, indicating some degree of correlation, the low Spearman's Rho coefficients do not allow us to reject the null hypothesis. This research, therefore, concludes that there is no significant correlation between the two variables. However, an overall positive relationship, albeit weak, is observed.

Plausible explanations for this lack of significant correlation between these two variables include score equalization via independent study, ACT compared to SAT test administration, and impact of population size on school funding. The first two factors come into play because Illinois is primarily an ACT-state, which implies that students choosing to take the SAT are among the top performers already with their eyes 
on the prestigious East-Coast schools where SAT test is preferred. In this case, the SAT data that we collected off of the Illinois Report Card website would not be an accurate representation of the entire high school population of the state or strata. However, bringing in the third possible explanation: the slightly higher Spearman's Rho coefficient when we combine the data for all three strata suggests that population size and respective district school funding do have some (positive) effect on SAT scores; on the overlaid graph, the rural district average SAT scores fall consistently the same or lower than scores from the other two strata.

The result of our study is similar to some of prior literature (Bryant, 2010). Like the EOIs that Bryant used, the SAT is a high-stakes test on which many students' college prospects can ride. Also like in Bryant's research, we found a low Spearman's Rho coefficient. This suggests that district school funding does not have a direct or significant impact on student success on high-stakes tests; a few possible explanations for this were discussed previously. Another reason for this finding is the ineffectiveness of school spending: a 2018 study in Kansas found no significant evidence that schools with reduced funding were significantly less efficient than others (Chakraborty and Poggio, 2018). This could help explain why students from rural districts in Illinois did not fare much worse on the SAT than those from urban districts.

Our finding might also imply that education spending by local governments is more ineffective in higher-funded schools (Chingos and Peterson, 2010). Future research could delve into how local district education funds are spent and how schools individually determine where the money should go. In addition, further studies involving different facets of education spending - including spending on technology - for students should be conducted. Our research also clearly demonstrates the need for a nation-wide standardized assessment as a systematic and consistent measure for academic performance. Considerable amount of time was spent on selecting which test score to use and managing data availability and comparability issues. The results were less than satisfactory. We did examine the results using different measures including PISA, ACT, NAEP scores, and, finally, back to SAT scores. This opens up an avenue for studies to be done to determine comparable standardized scores of student performance and how they relate to global measures like the PISA test, the TIMMS test, and nation-wide NAEP tests. We chose to study the state of Illinois because it had the most complete set of data at the time of our data collection. Expanding to other populations could be an opportunity for future studies.

\section{REFERENCES}

Biddle, B.J., \& Berliner, D.C. (2002). A Research Synthesis / Unequal School Funding in the United States. Retrieved from https://www.ascd.org/el/articles/-unequal-school-funding-in-the-unitedstates

Blagg, K., \& Chingos, M.M. (2017). Do Poor Kids Get Their Fair Share of School Funding? Retrieved from https://www.urban.org/sites/default/files/publication/90586/school_funding_brief.pdf

Boulding, K. (1972). The schooling industry as a possible pathological section of the American economy. Review of Educational Research, 42(1), 129-143.

Bryant, A.C. (2010). Funding equity in Oklahoma public schools and its impact on student academic achievement on algebra I end of instruction tests (Order No. 3445873). ProQuest Central. (856341530). Retrieved from https://search.proquest.com/docview/856341530?accountid=34939

Chakraborty, K., \& Poggio, J. (2008). Efficiency and Equity in School Funding: A Case Study for Kansas. International Advances in Economic Research, 14(2), 228-241.

Chingos, M.M., \& Peterson, P.E. (2011). It's Easier to Pick a Good Teacher than to Train One: Familiar and New Results on the Correlates of Teacher Effectiveness. Economics of Education Review, 30(3), 449-465. Retrieved from https://eric.ed.gov/?id=EJ918713

Darling-Hammond, L., \& Post, L. (2000). Inequality in teaching and schooling: Supporting high-quality teaching and leadership in low-income schools. In R.D. Kahlenberg (Ed.), A notion at risk: Preserving public education as an engine for social mobility (pp. 127-167). New York: The Century Foundation Press. 
Eger, A. (2017). Oklahoma slips to 47th in nation on annual educational quality ranking. Tulsa World. Retrieved from http://www.tulsaworld.com/news/education/oklahoma-slips-to-th-in-nation-onannual-educational-quality/article_0053bd86-0819-5cab-8eda-2edcfbff0594.html

Jackson, C.K., Johnson, R.C., \& Persico C. (2016, February 1). The Effects of School Spending on Educational and Economic Outcomes: Evidence from School Finance Reforms. The Quarterly Journal of Economics, 131(1), 157-218. https://doi.org/10.1093/qje/qjv036

Proximity. (2018, June 8). Illinois School District Demographics. Retrieved from proximityone.com/sd_il.htm

Recuero, L., \& Olaberria, E. (2018). Public spending in education and student's performance in Colombia. Proquest. http://dx.doi.org/10.1787/282d9700-en

Shippensburg University. (n.d.). Critical Values of the Spearman's Ranked Correlation Coefficient (rs). Webspace. Retrieved from http://webspace.ship.edu/pgmarr/geo441/tables/spearman\%20ranked $\% 20$ correlation\%20table.pdf

Wendler, E. (2018). Lawmakers Pass Rare Tax Increase for Education, But Funding Falls Short of Teachers' Demands. State Impact Oklahoma. Retrieved from https:/stateimpact.npr.org/ oklahoma/2018/03/29/lawmakers-pass-rare-tax-increase-for-education-but-funding-falls-short-ofteachers-demands/ 